
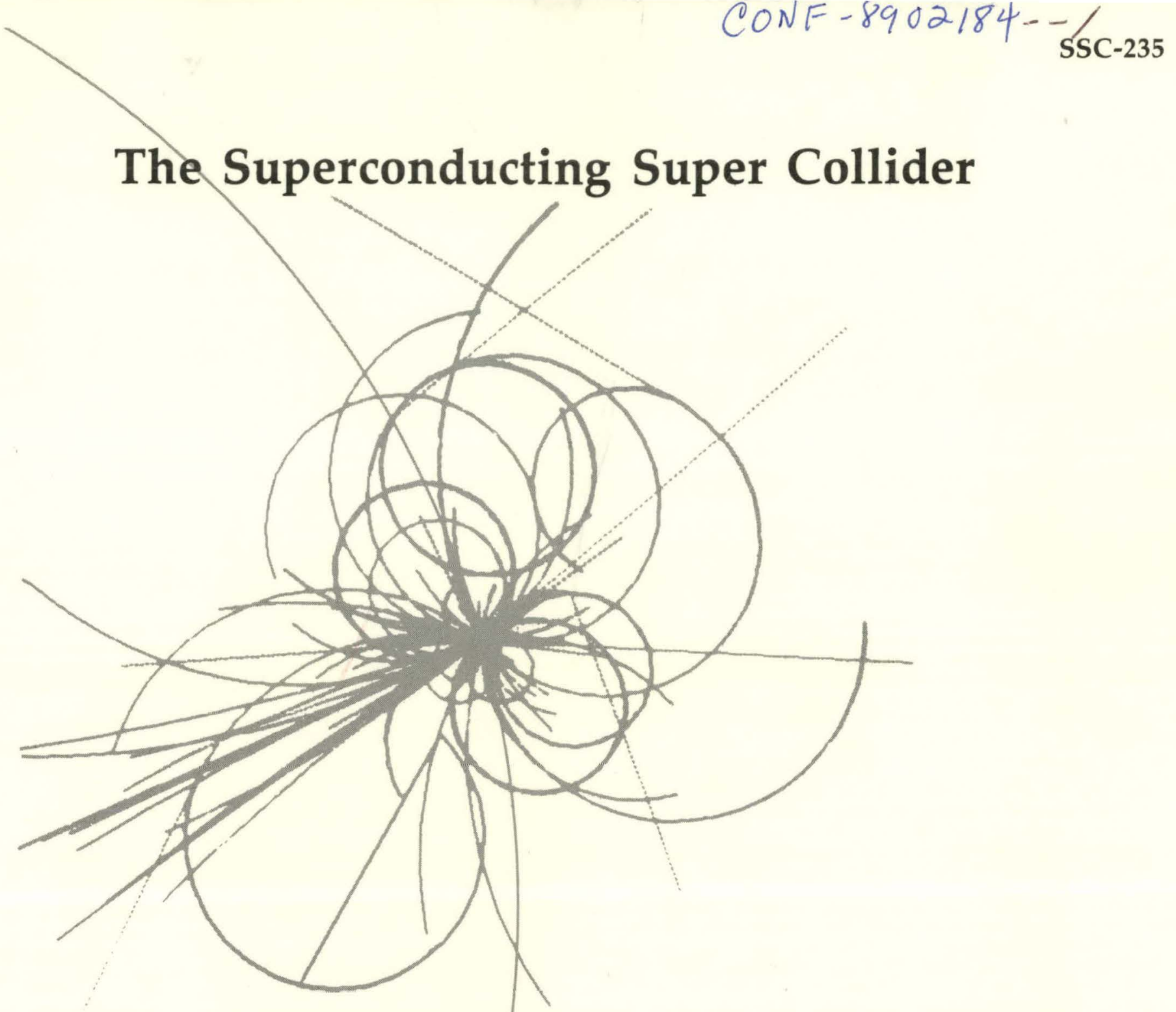

A Finite Element Analysis of an SSC Dipole Magnet (NC-9 Cross-Section)

\author{
Michael S. Chapman \\ SSC Central Design Group \\ Robert H. Wands
}

Fermi National Accelerator Laboratory

August 1989

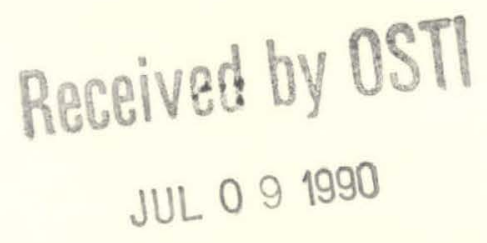




\section{DISCLAIMER}

This report was prepared as an account of work sponsored by an agency of the United States Government. Neither the United States Government nor any agency Thereof, nor any of their employees, makes any warranty, express or implied, or assumes any legal liability or responsibility for the accuracy, completeness, or usefulness of any information, apparatus, product, or process disclosed, or represents that its use would not infringe privately owned rights. Reference herein to any specific commercial product, process, or service by trade name, trademark, manufacturer, or otherwise does not necessarily constitute or imply its endorsement, recommendation, or favoring by the United States Government or any agency thereof. The views and opinions of authors expressed herein do not necessarily state or reflect those of the United States Government or any agency thereof. 


\section{DISCLAIMER}

Portions of this document may be illegible in electronic image products. Images are produced from the best available original document. 


\title{
A FINITE ELEMENT ANALYSIS OF AN SSC DIPOLE MAGNET* (NC-9 CROSS-SECTION)
}

\author{
Michael S. Chapman \\ SSC Central Design Group ${ }^{\dagger}$
}

SSC- -235

DE9 0013032

Robert $\mathrm{H}$. Wands

Fermi National Accelerator Laboratory

August 1989

\section{DISCLAIMER}

This report was prepared as an account of work sponsored by an agency of the United States Government. Neither the United States Government nor any agency thereof, nor any of their employees, makes any warranty, express or implied, or assumes any legal liability or rèsponslbility for the accuracy, completeness, or usefulness of any information, apparatus, product, or process disclosed, or represents that its use would not infringe privately owned rights. Reference herein to any specific commercial product, process, or service by trade name, trademark, manufacturer, or otherwise does not necessarily constitute or imply its endorsement, recommendation, or favoring by the United States Government or any agency thereof. The views and opinions of authors expressed herein do not necessarily state or reflect those of the United States Government or any agency thereof.

* Submitted to the Proceedings of the International Industrial Symposium on the Supercollider (IISSC), New Orleans, LA, February, 1989.

+ Operated by the Universities Research Association for the U.S. Department of Energy 


\title{
A FINITE ELEMENT ANALYSIS OF AN SSC DIPOLE MAGNET (NC-9 CROSS-SECTION)
}

\author{
Michael S. Chapman \\ SSC Central Design Group* \\ c/o Lawrence Berkeley Laboratory \\ Berkeley, CA 94720 \\ and \\ Robert H. Wands \\ Fermi National Accelerator Laboratory* \\ Batavia, IL 60510
}

\begin{abstract}
Finite element methods are used to calculate the mechanical behavior of an SSC superconducting dipole magnet under different loading conditions. A two-dimensional model of the NC-9 design (aluminum collars) has been developed and used to calculate the transverse deflertions and stresses in the dipole after assembly of the magnet, cooldown to $4.2 \mathrm{~K}$, and energization to $6.6 \mathrm{~T}$. Verification of the results with experimental measurements and observations, and limitations of the analysis, are also discussed.
\end{abstract}

\section{Introduction}

The Superconducting Super Collider (SSC) is a proposed high-energy synchrotron accelerator designed to achieve proton-proton collisions in the $20-\mathrm{TeV}$ range, The henrt of the machine will consist of two concentric rings, ench over 50 miles in circumiference, through which counter-rotating proton beams will be accelerated to velocities appronching the speed of light and brought into collision at interaction regions where detoctors will record the energy and matter created in the collision. To direct the bean, each particle storage ring will require approximately 4000 superconducting dipole magnets with a central field of $6.6 \mathrm{~T}$ at $4.2 \mathrm{~K}$. The dipoles, which are fully described in Reference 1, consist of superconducting coils, collars, yokes, and shells (collectively referred to as the "cold mass," Figure 1) assembled and placed in an insulating cryostat. Each dipole is to be 17 meters long and will have a cold mass cross section $27 \mathrm{~cm}$ in diameter,

* Operated by the Universities Research Association, Inc., for the U. S. Departmẹtt of. Energy. 


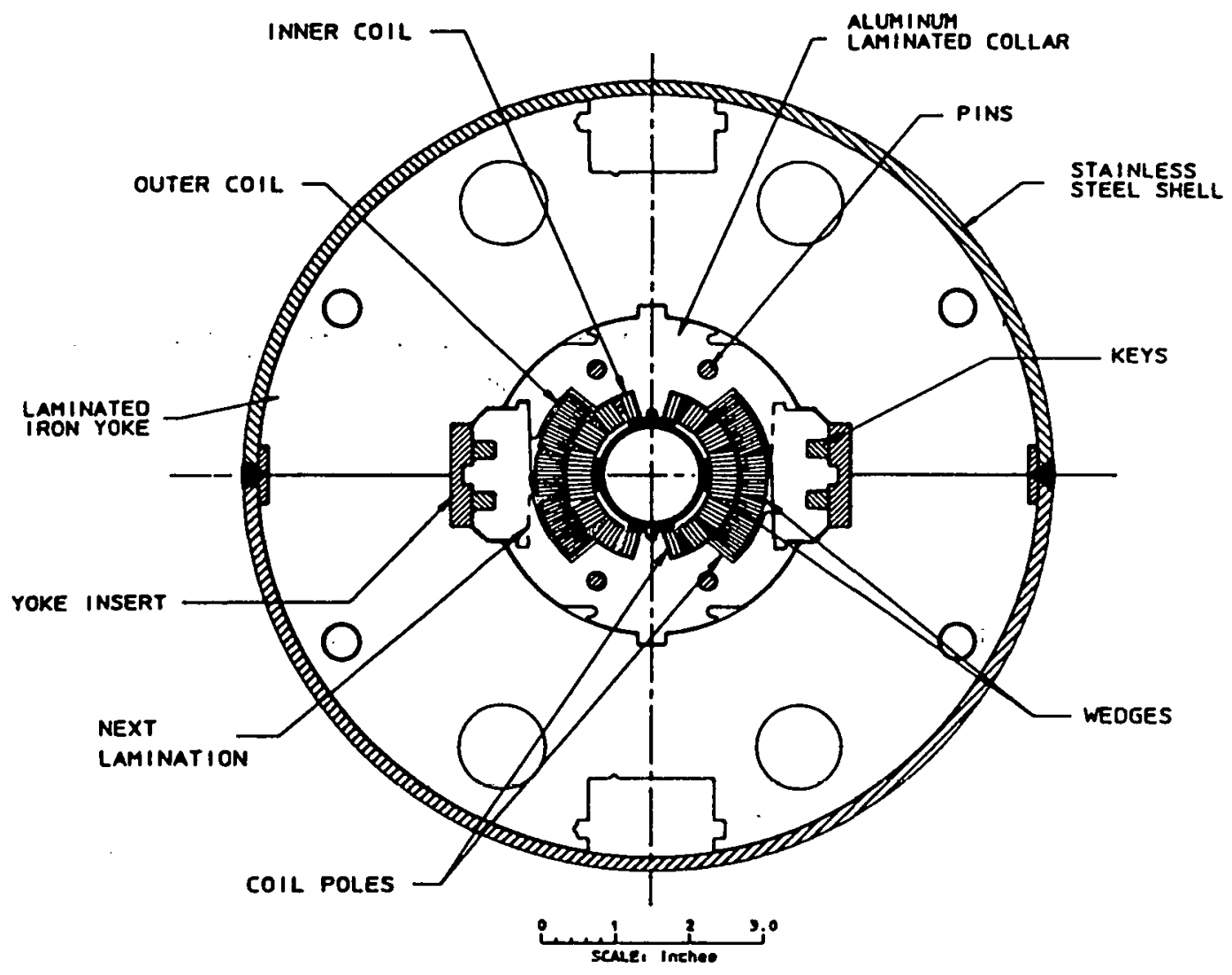

:Figure 1. Cross section of the SSC dipole "cold mass" (NC-9 design).

A successful dipole must create a sufficiently uniform central magnetic field to ensure stable beam grbits and must operate at the design field $(6.6 \mathrm{~T})$ without quenching (a rapid loss of superconductivity in the magnet conductor). To achieve these objectives, it is necessary to minimize coil motion during operation due to the Lorentz forces acting on the conductors. Excessive coil motion can distort the magnetic field and can cause enough frictional heat generation between conductors to initiate a quench. The NC-9 dipole design, which is one of two designs currently being considered for use in the SSC, uses laminated aluminum collars tightly clamped around the coils and supported by the yoke. The collars restrain coil motion and provide azimuthal precompression to the coils, which prevents minute strand-to-strand sliding in the conductor.

"Hère, we use the ANSYYS finite element code (a trademark of Swanson Analysis Systems) to examine the adequacy of the support provided by the collars and yoke, and, in particular, we calculate the deflections and stresses in the dipole after assembly of the magnet, cooldown to $4.2 \mathrm{~K}$, and energization to $6.6 \mathrm{~T}$.

\section{The Model}

The finite element model created for the analysis of the NC-9 cross section is shown in Figure 2 with some.portions of the collar shown separately for clarity (see below). The model uses two-dimensional isoparametric solid quadrilateral and triangular plane stress elements to model the individual components of the dipole, as well as compression-only "gap" elements that permit separation and frictionless sliding between components. The bilinear stiffness of the gap elements necessitates the use of iterative solution methods and causes the mechanical response of the system to be nonlinear. 


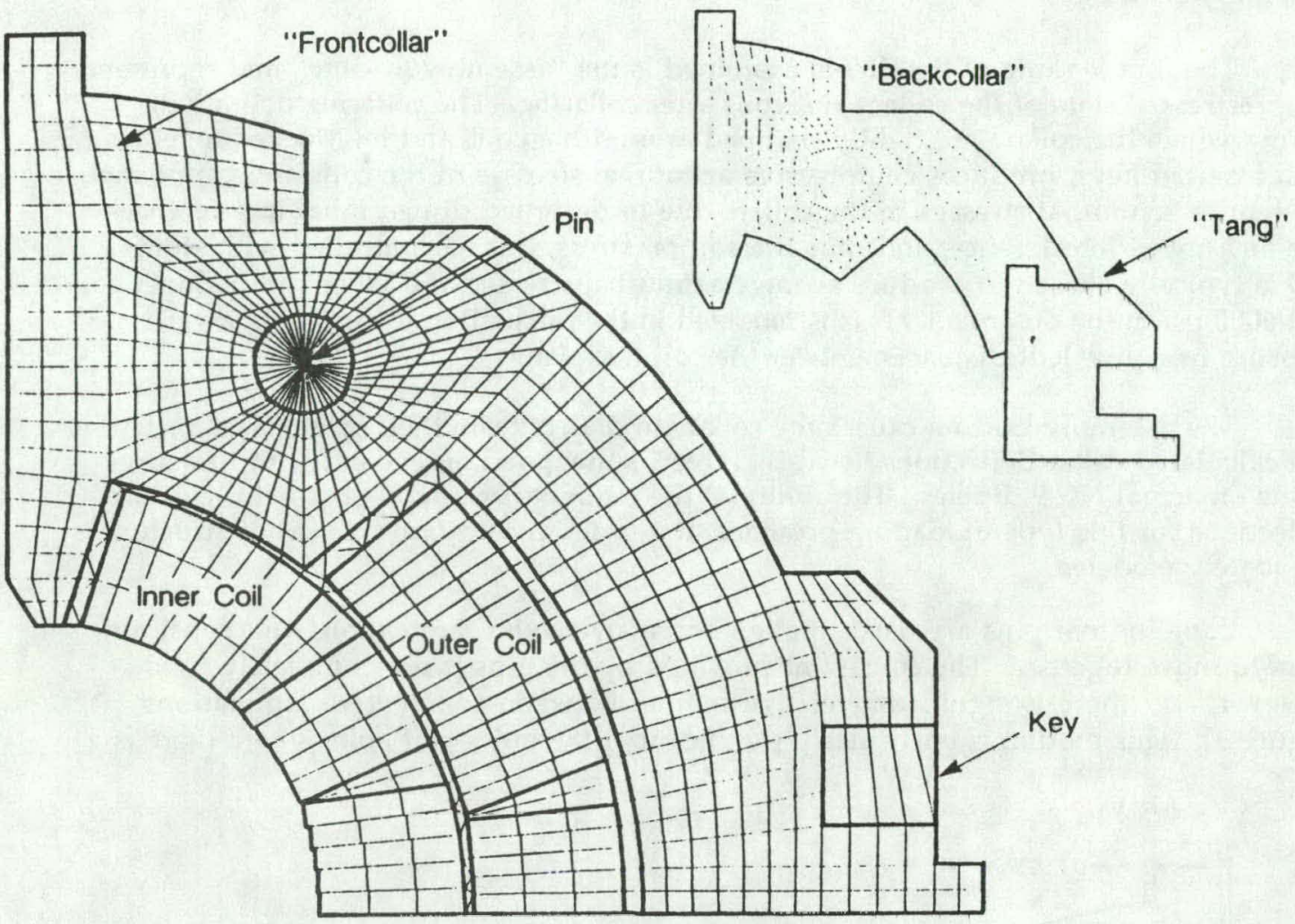

Figure 2. Finite element model of the NC-9 dipole. The "back collar" and "tang" pieces represent the next lamination longitudinally and are superimposed over the "front collar" piece.

The coils are modeled as individual turns of insulated superconducting cable and copper wedges. Each turn has three elements through the radial thickness and one element through the azimuthal thickness. For the majority of the calculations, the coils are treated as elastic, and isotropic, with a modulus of elasticity of $1.5 \times 10^{6} \mathrm{psi}$. This represents an approximation to the actual physical properties of the coil, which are very complicated due to its composite structure (multiple-strand twisted cable wrapped with Kapton insulation and epoxy-impregnated fiberglass). The calculated coil stresses, therefore, should be considered only qualitatively.

The collar assembly consists of alternating collar laminations tightly clamped together around the coils. The basic unit of the interlocking assembly consists of four collar pieces (two successive laminations), arranged as shown in Figure 1. The collars are interlocked with inserted keys and pins. In the analysis, the collars are modeled in three separated pieces: "front collar," "back collar," and "tang," which, when appropriately constrained, permit treatment of the problem in one quadrant. The models directly include the keys, and pins, as well as all specified dimensional clearances between the different components. The yoke/skin assembly has not been included in the finite element model because the yoke/collar contact point for the NC-9 design is well defined at the horizontal midplane, which permits treatment of the yoke as a boundary condition on the collars.

Loadings studied include the stresses and deflections after assembly ("assembly loading"), insertion into the yoke, cooldown to $4.2 \mathrm{~K}$, and energization to $6.6 \mathrm{~T}$. These loadings will be discussed separately in the following sections. 


\section{Assembly Loading}

The first loading of the dipole examined is the "assembly loading" and represents the prestressed state of the collars and coils after collaring. The collaring operation, during which the collars are tightly clamped around the coils and interlocked together with inserted keys, produces compressive azimuthal stresses in the coils and counteracting tensile azimuthal stresses in the collars due to designed dimensional interferences. The amount of interference, and thus the coil prestress, can be controlled with shims and is typically chosen to produce average azimuthal stresses of $8000 \mathrm{psi}$ in the inner coil and $6000 \mathrm{psi}$ in the outer coil. This is modeled in the calculation by applying a vertical pressure or equivalent displacements at the coil midplane.

The assembly loading causes the collars to deflect from their original geometry. The calculated collar deflections listed in Table 1 show good agreement with measurements on actual NC-9 dipoles. The ability of the model to accurately predict the collar deflections for this type of loading provides first-order verification that collar structure is adequately modeled.

Longitudinal pins are used to align successive collar laminations and constrain them to move together. The constraint provided by the pins is not completely rigid, however, and there is significant relative motion between consecutive laminations (Figure 3 ). This motion is particularly significant at the outer-coil pole, where there is a

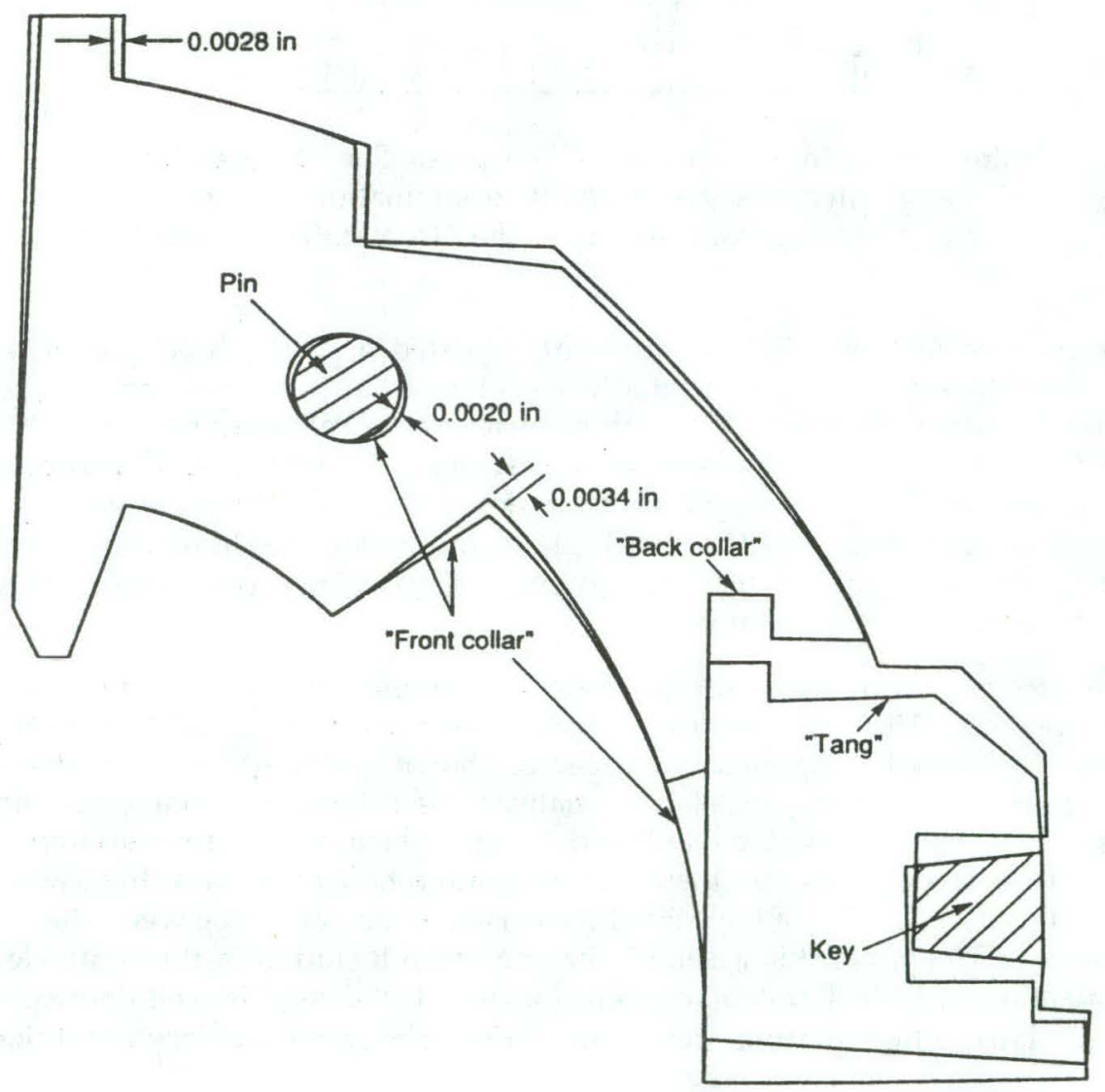

Figure 3. Relative motion between successive collar laminations due to assembly loading. 
Table 1. Calculated and Measured Collar Deflections After Assembly.

\begin{tabular}{lcc}
\hline \hline & \multicolumn{2}{c}{ (Change in collar diameter $\times 0.001$ inch) } \\
\cline { 2 - 3 } & Vertical Deflection & Horizontal Deflection \\
\hline Finite element calculation & 29.0 & 2.0 \\
Measured values & $29.0-35.0$ & $0.0-5: 0$ \\
\hline
\end{tabular}

$\sim 0.003$ inch relative motion between consecutive laminations such that the outer-coil pole is only fully contacted by every other collar lamination. Experimental confirmation of this result has been provided by measurements on magnets using pressure-sensitive paper and by observations on actual magnet cross sections. This result raises doubts about the adequacy of the outer-coil pole support and suggests a possible cause of the outer-coil training seen in the majority of NC-9 model magnets. A magnet will be tested in the near future employing a 0.060 -inch thick stainless steel shim at the outer coil pole designed to "bridge" across the non-contacting lamination. It is hoped that this will make the support of the outer coil more uniform from lamination to lamination.

The calculated collar stresses for the assembly loading indicate areas of high tensile stress at the keyways and the outer pole. The areas of high stress are very localized and are caused by geometrical stress raisers. These stress raisers have been analyzed separately and have been found to be sufficiently localized to not compromise the performance of the collars. ${ }^{2}$

\section{Insertion into the Yoke/Horizontal Force Loading}

The NC-9 design calls for a room-temperature interference fit between the collared coil assembly and the yoke at the collar keyways on the order of 0.015 inch on the diameter. Because of this dimensional interference, it is necessary to compress the collared coil to insert it into the yoke. In the analysis, the insertion into the yoke is modeled by the application of an inward horizontal force to the collars at the keyways. The model calnulates an inward collar deflection of 0.0027 inch on the diameter for an applied force of 1000 pounds. This compares very well with measured values of 0.0025 inch for the same loading, providing additional evidence that the collar stiffness is accurately modeled. The distortion of the coils produced by this loading introduces significant bending stresses into the coil. The change in azimuthal stress in the inner coil due to this loading is shown in Figure 4. Although the average stress at the coil pole remains largely unchanged, a large stress gradient is developed across the pole. For an applied force of 5000 pounds (which is closer to the actual loading applied to the magnets) the increase in stress at the inner radius of the inner coil is $6000 \mathrm{psi}$. As the inset to Figure 4 indicates, the stress gradients developed in the coil due to the horizontal force are analogous to those developed in a thick cylinder under similar loading.

\section{Cooldown}

As the magnet is cooled to $4.2 \mathrm{~K}$, differential thermal contraction between various materials in the dipnle produce changes in stress in the assembly. For the NC-9 design, aluminum collars are used instead of stainless stepl collars in an effuit to minimize coil prestress loss during cooldown. 


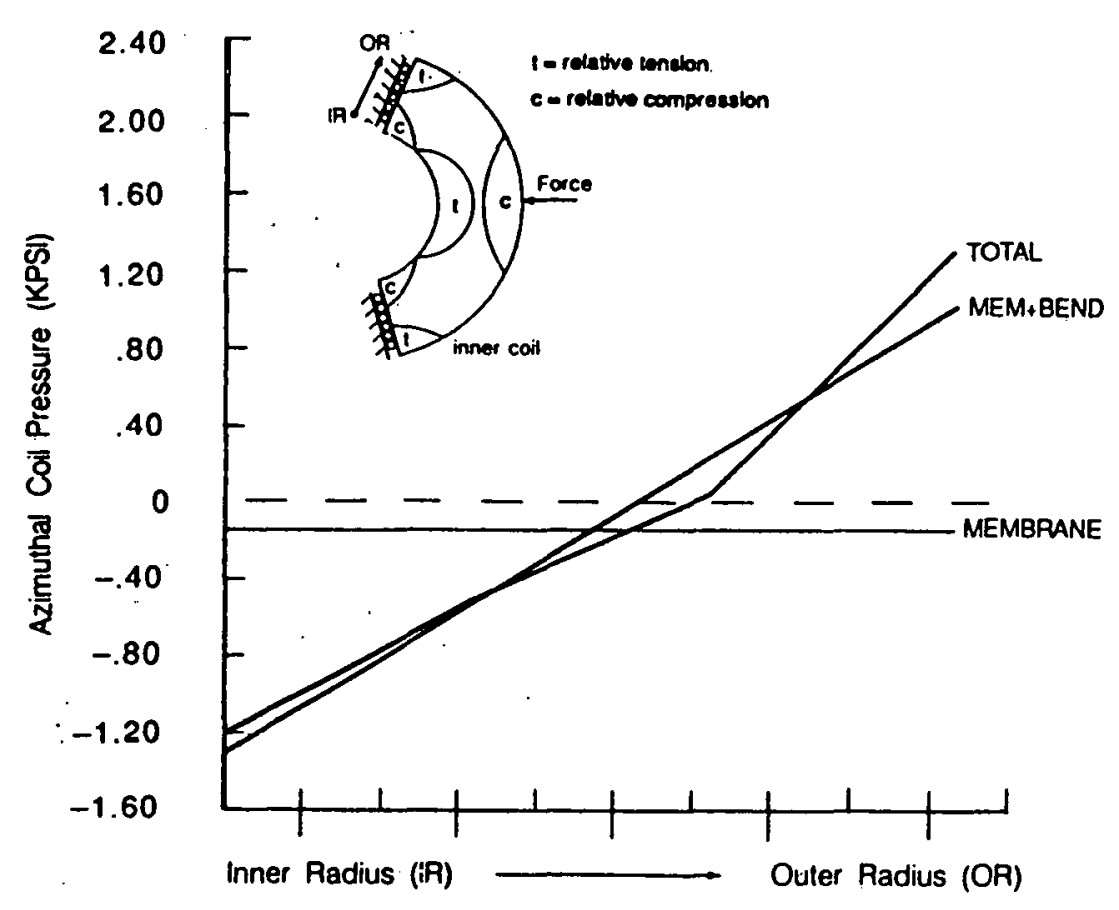

Figure 4. Change in inner coil azimuthal stress at the pole due to a 1000 pound inward force applied at the horizontal collar midplane. TOTAL refers to the actual calculated stress change; MEMBRANE represents the average stress change across the pole; MEM+BEND represents a linear fit to actual calculated stress change ( $A$ positive stress change indicates a loss in compressive stress).

Calculation of the change in coil stress during couldown is very sensitive to the specified coefficient of thermal contraction and the specified change in the modulus of elasticity with temperature for the coils. There are few measurements of these properties for the SSC coils, but it is generally thought that the coefficient of thermal contraction for the coils is similar to that for aluminum and that the coil modulus either increases (perhaps up to $4.0 \times 10^{6} \mathrm{psi}$ ) or remains constant at $1.5 \times 10^{6} \mathrm{psi}$. The calculation uses a thermal contraction coefficient identical to that for aluminum and a coil modulus that does not change with temperature.

As expected, the model calculates a negligible change in coil stress during cooldown using the above-specified properties. The change in coil stress is measured in magnets using pressure gauges placed at the coil poles. Two different types of gauges are used to measure coil stress: one developed at Brookhaven National Laboratory (BNL) ${ }^{3}$ and one developed at Lawrence Berkeley Laboratory (LBL). Measurements of the change in coil stress during cooldown vary from an increase of 1500 psi for BNL-type gauges to a decrease of 1500 psi for LBL-type gauges. It is hoped that the inconsistency in the measurements will be resolved in future magnet tests. 


\section{Lorentz Loading}

The magnetic field in the dipole produces large Lorentz forces on the currentcarrying conductors. These forces have a radial outward component, which tends to expand the collars horizontally, and an azimuthal component directed toward the coil midplanes, which tends to decrease the coil prestress at the pole. Reducing collar deflections due to these forces and maintaining coil prestress at the poles are two very important elements of dipole mechanical design.

The finite element model is used to calculate the loss in prestress at the coil poles and collar deflections at different magnet currents. Energization is simulated in the models by applying independently calculated Lorentz forces directly to the conductor nodes. 4

Two limiting cases of yoke support of the collar are examined: no yoke support and infinitely rigid yoke support. For the infinitely rigid yoke support, the collars are prevented from expanding horizontally by imposed boundary conditions at the horizontal midplane of the collars and at the keyways.

The calculated collar deflections at full field for these different cases are listed in Table 2. Although the yoke model for the NC-9 dipole has not been explicitly included for this calculation, it is possible to determine the collar deflections with the yoke support by using superposition of the collar deflections for the unsupported case and the reaction forces developed at the constraints for the rigidly supported case along with the calculated horizontal stiffness of the yoke (calculated separately) 5 Such a superposition yields a diametral deflection of 0.0026 inch of the horizontal midplane at full field. The horizontal component of the total applied Lorentz force is 3970 pounds per quadrant per longitudinal inch. For the unsupported collars, this resultant is, of course, completely reacted by the vertical collar midplanes. For the infinitely rigid yoke support, 59\% of the resultant is rencted by the applied constraints, and the other $41 \%$ is reacted by the vertical collar miplanes. In the case of the actual yoke support, superposition indicates that $44 \%$ is reacted by the yoke and skin, with the remaining $56 \%$ being reacted by the vertical collar midplane.

The calculated loss in coil stress at the poles for the supported NC-9 magnet is shown in Figure 5 along with measured values obtained using BNL-type coil pressure gauges. A first-order verification of the calculated loss in stress at the inner coil is obtained using a method developed by Tollestrup 6 in which the coils are modeled by a series of springs, one per conductor, with the azimuthal Lorentz forces applied at each junction of two springs. Using this model, the stress loss at the inner pole of the NC-g is given by

Table 2. Calculated Collar Deflections and Change in Azimuthal Coil Stress Due to Energizntion to $6.6 \mathrm{~T}$.

\begin{tabular}{|c|c|c|c|c|}
\hline & \multicolumn{2}{|c|}{$\begin{array}{c}\text { (Change in collar } \\
\text { diameter } \times 0.001 \text { inch) }\end{array}$} & \multicolumn{2}{|c|}{ (psi) } \\
\hline & $\begin{array}{l}\text { Vertical } \\
\text { Deflection }\end{array}$ & $\begin{array}{l}\text { Horizontal } \\
\text { Deflection }\end{array}$ & $\begin{array}{c}\Delta \sigma \\
\text { Inner Coil }\end{array}$ & $\begin{array}{c}\Delta \sigma \\
\text { Outer Coil }\end{array}$ \\
\hline Constrained collars & -2.4 & 0.0 & 2860 & 1100 \\
\hline Unconstrained collars & -9.5 & 9.5 & 3500 & 715 \\
\hline
\end{tabular}




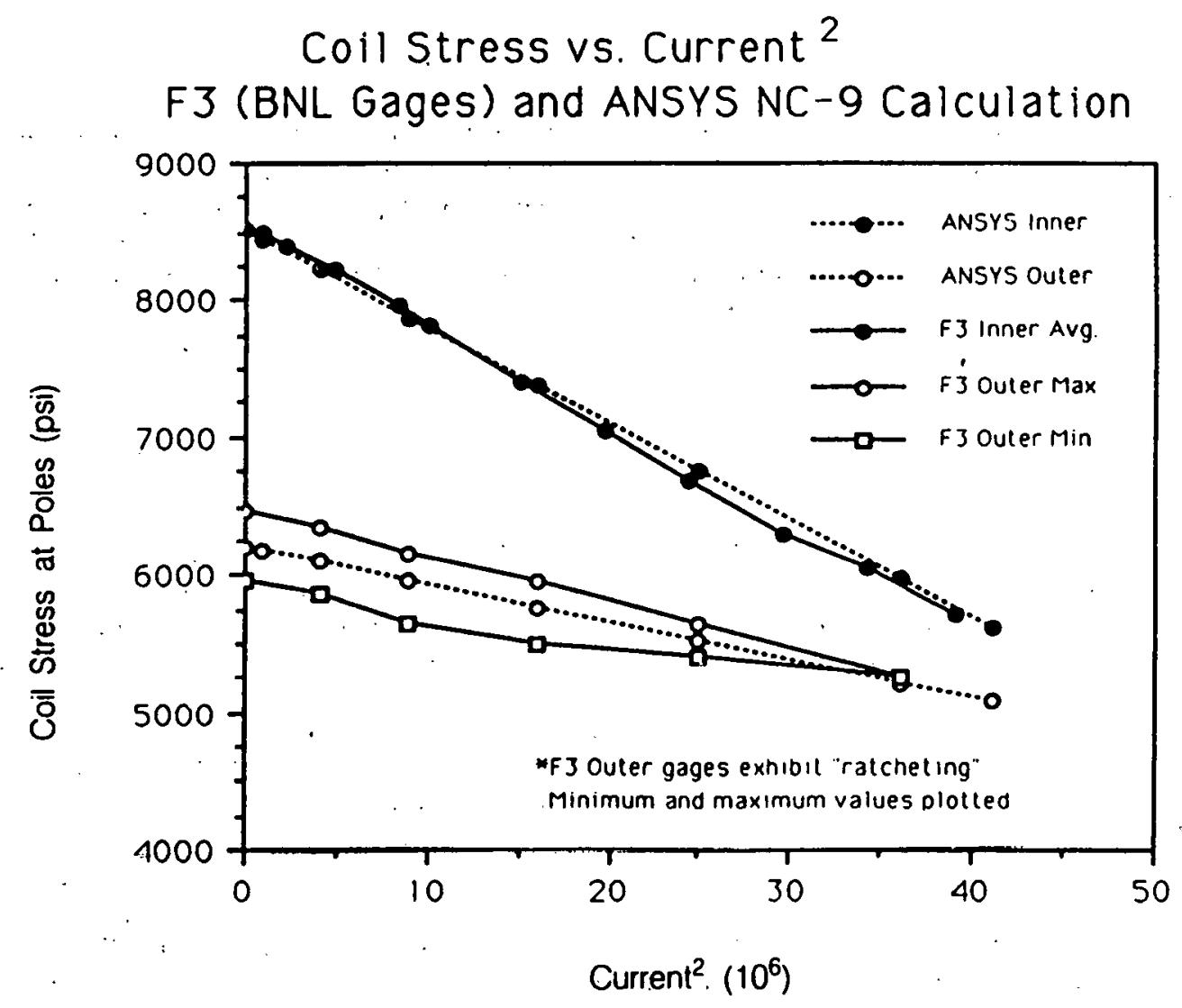

Figure 5. Calculated and measured change in average azimuthal coil stress at the poles at different magnet currents. Measured values obtained on NC-9 prototype magnet F3 using BNLtype gauges and reflect relative stress changes rather than absolute stress.

$$
\Delta \sigma_{\text {pole }}=\left(F_{\text {total }} / 3 A\right)(2 N+1) /(N+1)=3200 \text { psi, }
$$

where $F_{\text {total }}$ is the total azimuthal Lorentz force for the inner coil (1850 pounds/longitudinal inch), $N$ is the total number of turns (16), and $A$ is the area of inner coil $(0.37$ square inch/longitudinal inch). The smaller stress loss measured with the BNL gauges and calculated by the finite element model (which both indicate a loss of -2700 psi at 6400 amperes) is attributable to the elasticity of the collars, which is not included in the spring model. Although the finite element calculation of the coil prestress loss agrees well for this type of gauge, it should be noted that there is generally poor agreement with the measurements obtained using the LBL-type gauges. These gauges typically indicate a prestress loss of 5000-9000 psi at full field. The discrepancy between the two types of gauges is not currently understood. It is hoped that it will be resolved following further tests of the two types of gauges. At this point, all that can be said is that the finite element calculation and the simple spring model lend support to the BNL-type gauge results.

Although the average change in coil stress loss is not substantially different between supported and unsupported models, the peak stress loss is much greater in the unconstrained model, due to increased bending stresses in the coils caused by the increased deflection of the collars. Figure 6 shows the stress loss across the inner-coil pole face due to energization. For unsupported collars, the calculated change in stress varies from a decrease of $11000 \mathrm{psi}$ at the inner radius to an increase of $3600 \mathrm{psi}$ at the outer radius. While these calculated stresses should be interpreted only qualitatively, it is clear that the support offered by the yoke is essential in maintaining azimuthal prestress at the 


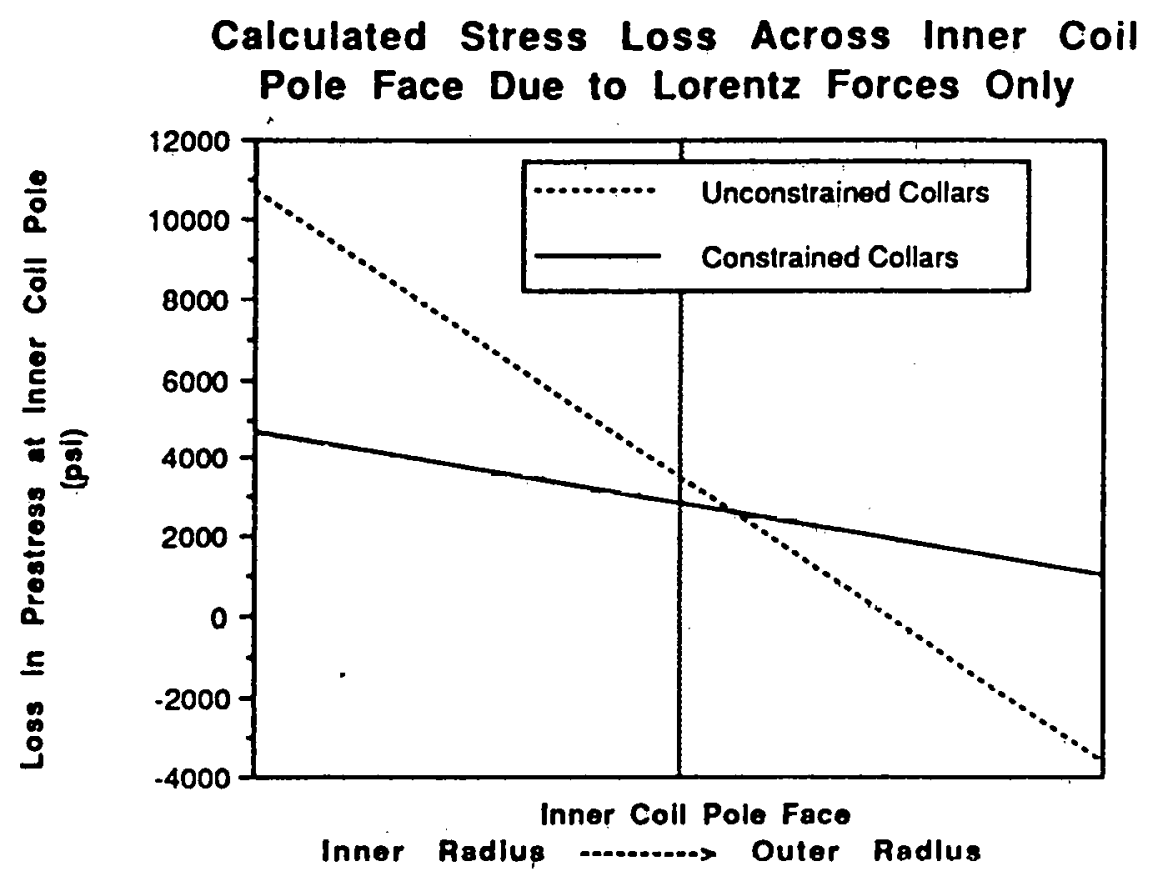

Figure 6. Calculated stress loss at $6.6 \mathrm{~T}$ across the inner coil pole face.

inner radius of the inner coil. Even in the limiting case, in which the collars are rigidly constrained from horizontal expansion, bending stresses are developed in the inner coil due to the vertical deflection of the collars and horizontal compression of the outer coil and the collar itself such that the inner radius loses 5000 psi, or 1800 psi more than the average.

\section{Summary}

The finite element model used in this analysis appears to accurately capture the two-dimensional mechanical behavior of the NC-9 dipole, despite the relatively simplc mechanical model utilized for the coil. As with all finite element calculations based on displacement formulations, one should have more confidence in the calculated deflections than in the calculated stresses. This is particularly true in this case because the material properties of the coil are in reality much more complex than specified in this analysis. Nonetheless, the calculations agree very well with the measurements. In addition, the analysis has focused attention on the support of the outer-coil pole provided by the laminations as well as on the difficulty of maintaining uniform stresses in the coil because of the collar elasticity.

Ongoing analysis efforts will incorporate nonlinear and orthotropic coil material properties into the model as they become available. Out-of-plane effects caused by longitudinal strains in the magnet will also be examined.

\section{Acknowledgments}

We wish to thank Bob Schermer (CDG) for his assistance and guidance in these analyses, and Julian Cortella (CDG) and Elizabeth Scholle (CDG) for their participation in this work. We would alsn like to thank Valerie Kelly and Annie Calinog for their skillful assistance in preparing this manuscript, as well as Kate Metropolis for her editorial assistance. 


\section{References}

1. J. D. Jackson, ed., "Conceptual Design of the Superconducting Super Collider, Attachment B," SSC-SR-1020, March 1986.

2. J. M. Cortella, Areas of High Local Stress in Dipole Components, SSC/CDG Report MD-TA-113, January 1989.

3. C. L. Goodzeit, M. D. Anerella and G. L. Ganetis, "Measurement of Internal Forces in Superconducting Accelerator Magnets with Strain Gauge Transchucers," IEEE Conference, Vol. 25, No. 2, March, 1989.

4. S. Caspi and M. Helm, "Lorentz Forces for LBL, NC-9 Dipole Cross Section," LBL Report LBID-1304, July, 1987.

5. J. M. Cortella, and M. S. Chapman, "A Finite Element Analysis of an SSC Yoke Used for Mechanical Support of the Collared Coil," SSC/CDG Report SSC-N-568, December, 1988.

6. A. Tollestrup, "Superconducting Magnets," AIP Conference Proceedings: Physics of High Energy Particle Accelerators (Fermilab Summer School, 1981). 